\title{
Effective Heterogeneous Photocatalytic Degradation of Crystal Violet Dye Using Manganese Ferrite Nanoparticles
}

\author{
Humaira Khan ${ }^{* 1}$, Aamna Balouch ${ }^{2}$, Kaniz Fatima Soomro ${ }^{1}$, Huma Shaikh ${ }^{2}$, \\ Saba Naz ${ }^{1}$, Aftab Ahmed Kandhro', Muhammad Qasim Samejo ${ }^{1}$ and \\ Nusrat Naeem Memon ${ }^{1}$ \\ ${ }^{1}$ Dr. M. A. Kazi Institute of Chemistry, University of Sindh, Jamshoro, Sindh, Pakistan. \\ ${ }^{2}$ National Center of Excellence in Analytical Chemistry, University of Sindh, Jamshoro, Sindh, Pakistan. \\ *Corresponding Author Email: humairaskhan81@yahoo.com.pk \\ Received 15 April 2019, Revised 21 June 2019, Accepted 24 June 2019
}

\begin{abstract}
A novel catalyst of $\mathrm{MnFe}_{2} \mathrm{O}_{4}$ manganese ferrite nanoparticles (MFN) was synthesized by simple co-precipitation method and successfully used as an efficient heterogeneous photocatalyst following Langmuir-Hinshelwood kinetic approach for the rapid photocatalytic degradation of organic dyes such as Crystal Violet (CV). Several techniques like, Fourier transform infrared (FTIR), X-ray diffractometer (XRD), scanning electron microscope (SEM) and energy dispersive $\mathrm{X}$-ray (EDX) were used to characterize the synthesized heterogeneous photocatalyst. The outcomes of the characterization established that the MNF can be competently synthesized with the size ranging between 20 to $50 \mathrm{~nm}$, using sodium dodecyl sulphate (SDS) as stabilizer. UVvisible spectrophotometer was used for monitoring $\mathrm{CV}$ dye photodegradation. Different controlling analytical parameters such as dosage of MFN photocatalyst, concentration of CV dye, time and $\mathrm{pH}$ were optimized to explore the potential application of newly synthesized catalyst MFN for the maximum photodegradation of CV dye. The kinetics of reaction mechanism was also analyzed by plotting Eley-Rideal model and Langmuir-Hinshelwood model. The MFN was found to be an environmental friendly, highly economical and effective heterogeneous photocatalyst with rapid $>90 \%$ efficiency to degrade the dye under investigation and easily could be regenerate with the help of magnet for successive uses.
\end{abstract}

Keywords: $\mathrm{MnFe}_{2} \mathrm{O}_{4}$ nanoparticles, Heterogeneous photocatalyst, Crystal violet degradation, UV light.

\section{Introduction}

The residues of various dye-based industries are the chief toxins to make water polluted and cruelly affect all living organism in ecosystem by resulting health hazardous substances [1-2]. Colored organic dyes generally have complex aromatic molecular structures, which make them more stable and nonbiodegradable. Crystal Violet (CV), a cationic triphenylmethane (Fig. 1) is a very popular dye and has been employed in veterinary medicine as a biological stain. It is also used to provide deep violet color in textiles, cosmetics, paint and varnishes, food, pulp and paper, plastics and ink industry [3-6]. Despite many uses, CV has been reported as having unfavourable effects. It acts as a mitotic poison, potent carcinogen and clastogene promoting tumor growth in some species of fish [7]. Hence, CV is of great concern to be effectively removed from industrial wastewaters to save the environment.

This organic dye can be decolorized by several methods including electrochemical, filtration, coagulation and adsorption, precipitation [8]. Currently, heterogeneous photocatalysis with 
hydrogen peroxide $\left(\mathrm{H}_{2} \mathrm{O}_{2}\right)$ in presence of light is an advanced oxidant process (AOP). AOP is a very successful technique to remove toxic contaminant from water [9-15]. In this method the $\mathrm{H}_{2} \mathrm{O}_{2}$ decompose to highly reactive hydroxyl radicals $\left(\mathrm{HO}^{\circ}\right)$ which decolorized the organic dyes in the presence of heterogeneous photocatalyst. The ferromagnetic material, iron-based nano catalyst is the emerging application in AOP that is widely examined due to its successful use in removing a broad range of common ecological organic and inorganic pollutants [16-19]. Ferrite catalysts due to its magnetic property can be reused and regenerated effortlessly [20-21].

In the current study, a simple and direct co-precipitation method for the synthesis of manganese ferrite nanoparticles $\left(\mathrm{MnFe}_{2} \mathrm{O}_{4}\right)$ and its nano-photocatalytic potential to degrade organic dye (crystal violet) was investigated. The characterization of the newly synthesized heterogeneous nano-photocatalyst MFN was made by Fourier transform infrared (FTIR), X-ray diffraction (XRD), energy dispersive X-ray (EDX) and scanning electron microscope (SEM). The percent degradation of the crystal violet dye was observed through UV-visible spectrophotometer. The effect of controlling analytical parameters such as dosage of MFN photocatalyst, concentration of $\mathrm{CV}$ dye, time and $\mathrm{pH}$ were also studied for the maximum percent degradation of CV dye. Approximately 92\% degradation of organic dye within a short time period was obtained. Due to simple synthesis and heterogeneous catalytic approach the MFN can be used as a low cost, environmental friendly and effective catalyst to photodegrade the dye under investigation.<smiles>CN(C)c1ccc(C(=C2C=CC(=[N+](C)C)C=C2)c2ccc(N(C)C)cc2)cc1</smiles>

Figure 1. Structure of crystal violet

\section{Materials and Methods Chemicals}

All chemicals used in the experiment were analytical grade and purchased from well know suppliers and used as received without any further purification. Metal precursors salts including manganese chloride $\left(\mathrm{MnCl}_{2}\right)$ and ferrous chloride $\left(\mathrm{FeCl}_{2}\right)$, sodium borohydrate $(\mathrm{NaBH} 4)$ and sodium dodecyl sulphate (SDS) were purchased from Sigma Aldrich. CV and $\mathrm{H}_{2} \mathrm{O}_{2}(30 \%$, w/v) were obtained from Merk (Germany). Ultrapure milli-Q water was used to prepare all standard solutions. The milli-Q water was obtained from milli- $Q$ water purification machine (Elga Co. USA). The apparatus were soaked in $10 \%$ solution of nitric acid for $24 \mathrm{~h}$. Next day, the glassware were washed thoroughly with de-ionized water and dried at $110{ }^{\circ} \mathrm{C}$ in an oven.

\section{Synthesis of MFN}

Manganese ferrite nanoparticles (MFN) with standard shape and size of 20-50 nm have been synthesized by simple co-precipitation method. In typical method suitable mass of precursor salts, $\mathrm{FeCl}_{2}$ and $\mathrm{MnCl}_{2}$ were mixed in 50 $\mathrm{mL}$ of $10 \mathrm{mmol}$ solution of SDS to form $2: 1$ mole ratio solution. The clear solution is obtained after 15 minutes sonication. After that $50 \mathrm{mg}$ of $\mathrm{NaBH}_{4}$ and $10 \mathrm{~mL}$ of $0.1 \mathrm{M} \mathrm{NaOH}$ was added. Then solution was sonicated for 30 minutes and sample was dried on electronic hot plate at $100{ }^{\circ} \mathrm{C}$. Furthermore it was calcinated in the furnace at $600{ }^{\circ} \mathrm{C}$.

\section{Photocatalytic degradation study of CV dye}

For photodegradation studies, 100 ppm stock solution of $\mathrm{CV}$ was prepared in milli $\mathrm{Q}$ water. For each dye degradation study, different amount of stock solution of $\mathrm{CV}$ were taken in glass container with the diameter $8 \mathrm{~cm}$ and treated with $1 \mathrm{~mL}$ of $\mathrm{H}_{2} \mathrm{O}_{2}(30 \%$, w/v) and known amount (50-200 mg) of newly synthesized nanophotocatalyst MFN. The total volume of the mixture was adjusted to $100 \mathrm{~mL}$ with milli Q water. The reaction mixture was sonicated for 30 min in dark to obtain the adsorption-desorption equilibrium between $\mathrm{CV}$ dye and MFN. Finally, 
the reaction dispersion was placed under $50 \mathrm{~W}$ Philips Mercury vapor lamp with constant stirring. The reaction mixture was irradiated by focusing the light directly onto the suspension at a distance $10 \mathrm{~cm}$. At a given time period, $5 \mathrm{~mL}$ of clear solution was taken out from the reaction mixture, separated with help of magnet and the decreased absorbance at $\lambda_{\max } 588 \mathrm{~nm}$ was monitored by UVvisible spectrometer model Biochrom Libra S22. The following formula was used to calculate the percentage of dye degraded:

$\%$ Degradation $=\left(C_{O}-C / C_{O}\right) 100=\left(A_{O}-A / A_{O}\right) 100$

Here $C_{O}$ is representing the initial concentration of dye, $C$ is the variable concentrations, $A_{O}$ is the initial absorbance, and $A$ is denoting the variable absorbance. The experiment was repeated by varying the parameters such as dosage of MFN photocatalyst, concentration of $\mathrm{CV}$ dye and $\mathrm{pH}$. Calibration curves were constructed for $\mathrm{CV}$ degradation, and all experiments were performed three times to verify the reproducibility of the results.

\section{Results and Discussion Characterization}

Initially IR spectra of synthesized nanophotocatalyst MFN was recorded by employ the ATR of a Thermo Nicolet Model Avatar 330 FTIR spectrometer with Omnic software and prepared with ZnSe cell (Fig. 2). The FT-IR spectrum shows broad absorption band approximately on $3400 \mathrm{~cm}^{-1}$ and the small band at $1300 \mathrm{~cm}^{-1}$ is due to stretching vibration of hydrogen bonding groups and $\mathrm{C}=\mathrm{O}$ stretching mode from the absorption of atmospheric moisture and $\mathrm{CO}_{2}$ on the surface of MFN [22-23]. The absorption bands appeared in between 500 to $1000 \mathrm{~cm}^{-1}$ is because of the metal-oxygen bond [23].

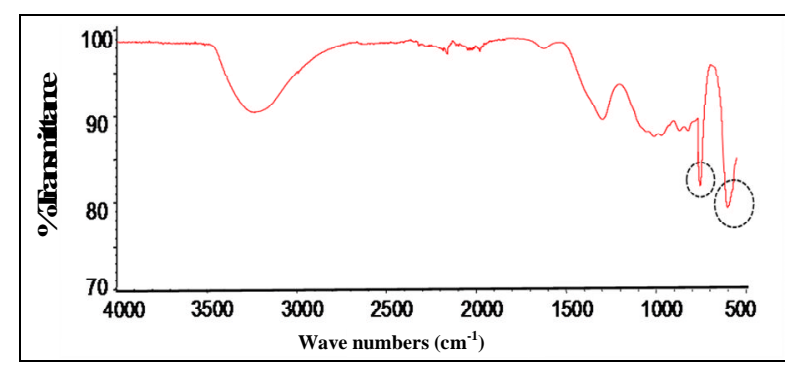

Figure 2. FTIR spectrum of manganese ferrite nanoparticles
The successful synthesis of MFN, its crystallinity and phase of particles was checked by using Advanced system (Bruker D8) with $10^{\circ} \mathrm{min}^{-1}$ scan rate and $\mathrm{Cu} \mathrm{K} \alpha$ irradiation $(\lambda=1.541 \AA) \mathrm{X}$ ray diffraction microscopy. The diffractrogram pattern shown in Fig. 3. The patterns present the bragg reflection planes (111), (311), (222), (400), (422) and (440), which verify the existence of single phase MFN with a face-centered cubic structure. All the peaks well coordinated with the reflections of the MFN in published research papers [24] and (JCPDS card No. 10-0319).

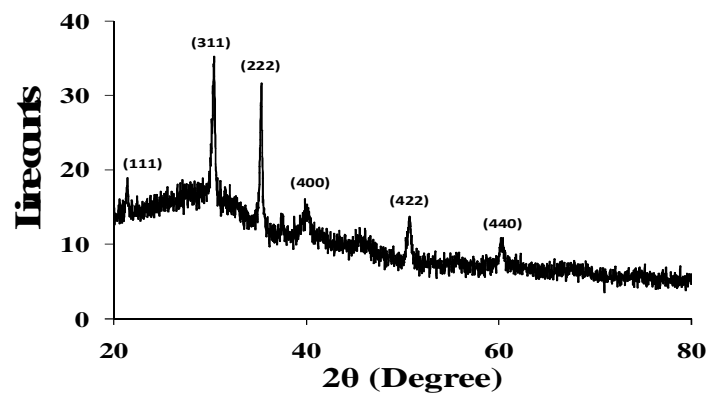

Figure 3. XRD pattern of manganese ferrite nanoparticles

The morphological features and topography of synthesized catalyst were studied by a Hitachi S2300 SEM at $25 \mathrm{kV}$ accelerating voltage. The microscope was equipped with an EDX analyser to examine the elemental composition of nano catalyst. The samples were carbon coated using an Edwards Scancoat Six machine to reduce the charging effect. The Fig. 4(A-B) shows low and high resolution SEM images. The particles are homogeneously distributed in size, having semispherical smooth surface and diameter of nanoparticles obtained from SEM micrograph are about 20-50 nm with greater distribution is $35 \mathrm{~nm}$.

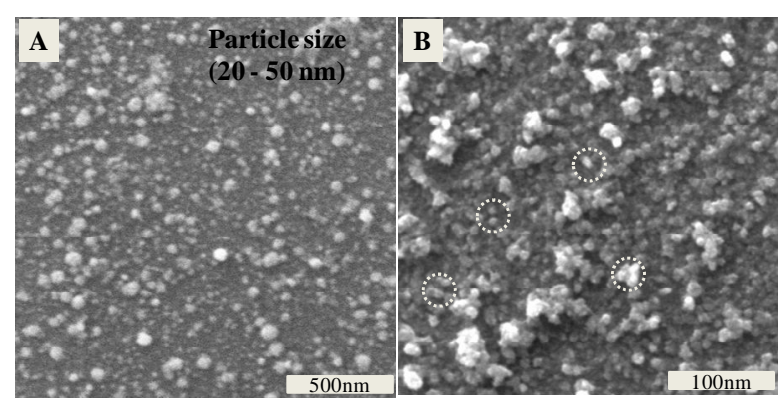

Figure 4. (A, B) SEM images of manganese ferrite nanoparticles with different magnification 
The EDX spectroscopy technique further contributes the valuable information about atomic concentration of various composite on top surface layers of the solid examined. The energy dispersive X-ray spectrum of newly synthesized MFN (Fig. 5) authenticates the presence of $\mathrm{Fe}, \mathrm{Mn}$ and $\mathrm{O}$ elements with the $\mathrm{C}$ substrate peak. The observed atomic percent of $\mathrm{Fe}, \mathrm{Mn}$ and $\mathrm{O}$ are 23.21, 13.57 and 49.97, respectively.

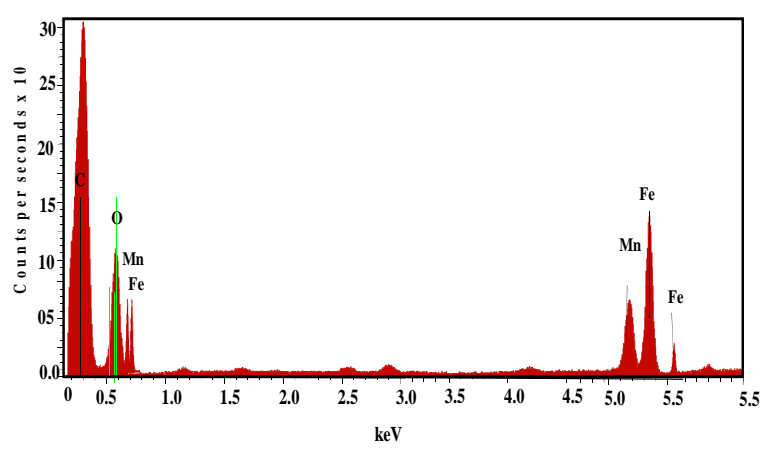

Figure 5. EDX spectrum of manganese ferrite nanoparticles

\section{Heterogeneous catalytic application of MFN for photodegradation of $\mathrm{CV}$}

The catalytic activity of the MNF has been investigated for the degradation of toxic organic dye $\mathrm{CV}$ in aqueous solution in the presence of the $\mathrm{H}_{2} \mathrm{O}_{2}$. In a typical process, manganese ferrite nanocatalyst was added in $100 \mathrm{~mL}$ aqueous solution of $10 \mathrm{mgL}^{-1} \mathrm{CV}$ and $1 \mathrm{~mL}$ of $\mathrm{H}_{2} \mathrm{O}_{2}(30 \%$, w/v). After every 5 minute degradation of $\mathrm{CV}$ was monitored by recording the absorption spectra using the UV-Visible spectrophotometer (Fig. 6). Fig. 6 shows almost complete degradation of $\mathrm{CV}$ dye within 60 minutes time period.

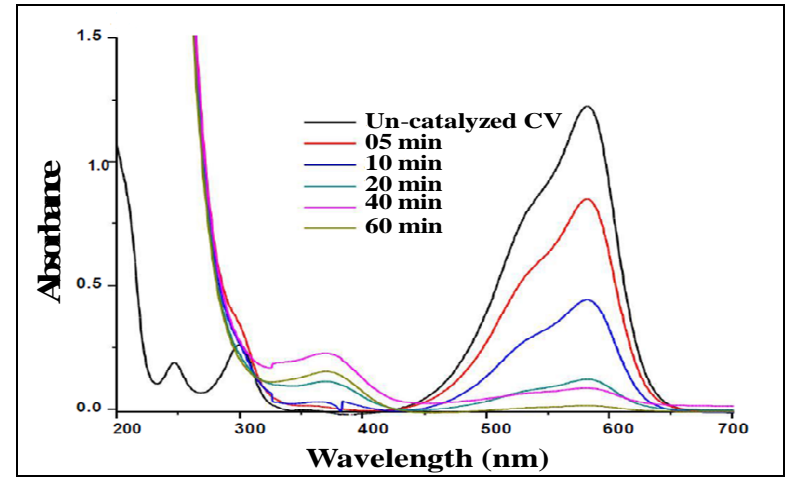

Figure 6. Effect of time for the photcatalytic degradation of $\mathrm{CV}$ dye
Initially to achieve the maximum degradation of $\mathrm{CV}$, different parameters including concentration of $\mathrm{CV}, \mathrm{pH}$ of reaction solution, reaction time and the dose of catalyst were optimized. Also, the kinetics of reaction was analyzed by plotting Eley-Rideal model and Langmuir-Hinshelwood model.

\section{Effect of dose of heterogeneous photocatalyst}

The effect of different amounts 0 to 200 $\mathrm{mg}$ of heterogeneous photocatalyst was investigated for the degradation of $10 \mathrm{mgL}^{-1} \mathrm{CV}$ solution with $1 \mathrm{~mL}$ of $\mathrm{H}_{2} \mathrm{O}_{2}(30 \%$, w/v) at $\mathrm{pH} 7.5$ for 120 minutes. The percentage degradation of $\mathrm{CV}$ dye only in presence of $\mathrm{H}_{2} \mathrm{O}_{2}$, without catalyst is just 35\% (Fig.7). It shows that in the absence of heterogeneous photocatalyst, $\mathrm{H}_{2} \mathrm{O}_{2}$ alone is not effectively work to oxidize the $\mathrm{CV}$ dye. Therefore, MFN as a catalyst is needed to activate $\mathrm{H}_{2} \mathrm{O}_{2}$. On the basis of these results, following reaction mechanism for the degradation of $\mathrm{CV}$ is proposed.

$$
\begin{aligned}
& \mathrm{MnFe}_{2} \mathrm{O}_{4}+\mathrm{H}_{2} \mathrm{O}_{2} \rightarrow \mathrm{MnFe}_{2} \mathrm{O}_{4}^{+}+\mathrm{HO}^{-}+\mathrm{HO}^{\bullet} \\
& \mathrm{H}_{2} \mathrm{O}_{2}+\mathrm{HO}^{\bullet} \rightarrow \mathrm{H}_{2} \mathrm{O}+\mathrm{HOO}^{\bullet} \\
& \mathrm{HOO}^{\bullet}+\mathrm{MnFe}_{2} \mathrm{O}_{4}^{+} \rightarrow \mathrm{MnFe}_{2} \mathrm{O}_{4}+\mathrm{H}^{+}+\mathrm{O}_{2}
\end{aligned}
$$

Oxygen and free radicals are generated with the aid of MFN which further reacts with CV dye to degrade it.

Furthermore, Fig. 7 shows that $\mathrm{CV}$ photodegradation increases with increases the heterogeneous photocatalyst concentration upto $150 \mathrm{mg}$ but decreases at $200 \mathrm{mg}$. It could attribute to the dosage of MFN increases the exposed surface area for adsorption of number of $\mathrm{CV}$ molecules also increases. Increased amount concentration of MFN is also effected by dimension of glass vessel. Increasing collision between molecules with increased amount of MFN may also cause to obstruct the light strike on MFN which ultimately reduces the efficiency of MFN to produce $\mathrm{HO}^{\circ}$. Secondly, the increase MFN concentration above the optimal range may cause the agglomeration of MFN particles which lead less active sites of MFN for degradation of CV. 


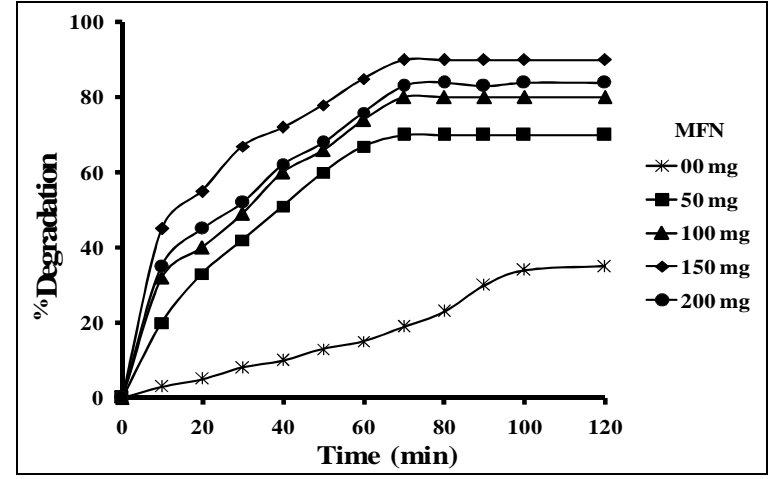

Figure 7. Effect of dose of MFN photocatalyst on the CV degradation

\section{Effect of CV dye concentration}

$100 \mathrm{~mL} \mathrm{CV}$ solutions of 10 to $50 \mathrm{mgL}^{-1}$ with $150 \mathrm{mg}$ of MFN at $\mathrm{pH} 7.5$ were used to examine the effect of initial CV dye concentration on photodegradation performance for 120 minutes. Fig. 8 shows that approximately $92 \%$ degradation for 10 to $40 \mathrm{mgL}^{-1} \mathrm{CV}$ dye, but the percentage degradation decreased for $50 \mathrm{mgL}^{-1} \mathrm{CV}$ solution. The decrease in degradation of $\mathrm{CV}$ dye can be explained by adsorption capacity of MFN catalyst, as the concentration of $\mathrm{CV}$ increases the active sits of MFN decreases. At higher concentration of dye more $\mathrm{CV}$ molecules are adsorbed at the surface of MFN catalyst which ultimately also hindered the production of $\mathrm{HO}^{\circ}$ and the light incident.

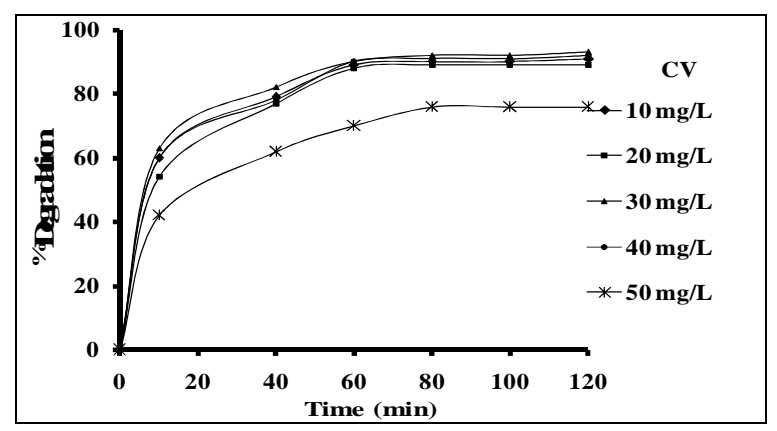

Figure 8. Effect of concentration of crystal violet on photodegradation

\section{Effect of the pH}

The $\mathrm{pH}$ effect on the photodegradation rate of $\mathrm{CV}$ dye was studied by taking $100 \mathrm{~mL}$ solution of $10 \mathrm{mgL}^{-1} \mathrm{CV}$ dye with $150 \mathrm{mg}$ of MFN for 120 min and the $\mathrm{pH}$ was varied from 3 to 9 by adding
$0.1 \mathrm{~N} \mathrm{NaOH}$ and $\mathrm{HCl}$. The percentage degradation is shown in Fig. 9. The percentage degradation was observed to increase rapidly from initial $\mathrm{pH} 3-5$ and maintained constant on further increase in $\mathrm{pH}$ range from 5 to 9 . This fact can be explained on the basis of adsorption behavior of MFN, usually affected by the $\mathrm{pH}$ of the solution. At $\mathrm{pH}<5$ the MFN exist in cationic form so they less interacted with the cationic $\mathrm{CV}$ dye due to electrostatic repulsion. On the other hand, at $\mathrm{pH}>5 \mathrm{MFN}$ exist in anionic form so they maximally interacted with cationic CV dye molecules due to electrostatic force of attraction. Additionally, only the CV dye molecules adsorbed at the surface of MFN catalyst can be degraded successfully. Consequently, the higher $\mathrm{pH}$ value can improve the adsorption capability of MFN for cationic CV dye molecules and so their catalytic potential.

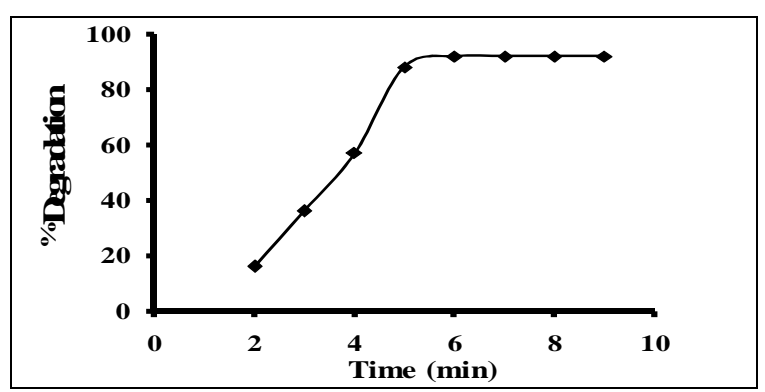

Figure 9. Effect of $\mathrm{pH}$ of reaction solution on photodegradation of crystal violet

\section{Kinetics mechanism of photocatalytic degradation}

Eley-Rideal model and LangmuirHinshelwood models were applied to determine the surface reaction mechanism. First Eley-Rideal model explains that during the course of reaction any one reactant is adsorbed at the surface of the catalyst and reacted with the other reactant present in the reaction mixture [25-26]. Then commonly applied kinetic model, Langmuir-Hinshelwood model was also studied for the heterogeneous catalytic reactions. Reaction followed LangmuirHinshelwood mechanism, once both reactants $(\mathrm{CV}$ and $\mathrm{H}_{2} \mathrm{O}_{2}$ ) adsorbed simultaneously onto the surface of catalyst and take a part in reaction. The rate determining step in the LangmuirHinshelwood mechanism is the surface reaction. Therefore, reactants adsorption at the surface of catalyst and the products dispersion from the 
surface of the catalyst should be faster than the reaction mechanism itself.

In typical method for LangmuirHinshelwood a broad concentration range of $\mathrm{CV}$ (5 to $60 \mathrm{mgL}^{-1}$ ) was treated with a constant concentration of $1 \mathrm{~mL}$ of hydrogen peroxide $\mathrm{H}_{2} \mathrm{O}_{2}$ $(30 \% \mathrm{w} / \mathrm{v})$ (Fig. 10A). In addition, for Eley-Rideal model, different concentrations of hydrogen peroxide $\mathrm{H}_{2} \mathrm{O}_{2}$ (0.3 to $2.1 \mathrm{~mL}$ of $30 \%$ w/v of $\mathrm{H}_{2} \mathrm{O}_{2}$ ) were examined with constant concentrations of $\mathrm{CV}$ (10 $\left.\mathrm{mgL}^{-1}\right)$ (Fig. 10B).

Figure 10 illustrated that the rate constant depends on the concentration of $\mathrm{H}_{2} \mathrm{O}_{2}$ and $\mathrm{CV}$ it was decreasing with increasing concentration of $\mathrm{CV}$. Therefore, this reaction of degradation of $\mathrm{CV}$ followed a Langmuir-Hinshelwood mechanism. Since in the rate determining step, the reactants (hydrogen peroxide $\mathrm{H}_{2} \mathrm{O}_{2}$ and $\mathrm{CV}$ ) adsorbed on the surface of catalyst $\mathrm{MFN}$ so the reaction starts between the generated free radicals $\mathrm{HO}^{\circ}$ and $\mathrm{CV}$ and at the end of this step reaction, the product desorbs from the catalyst surface to reproduce free active sites on the catalyst surface. Moreover, the diffusion of the reactants to the surface of the catalyst MFN and adsorption-desorption equilibrium are assumed to be very fast.

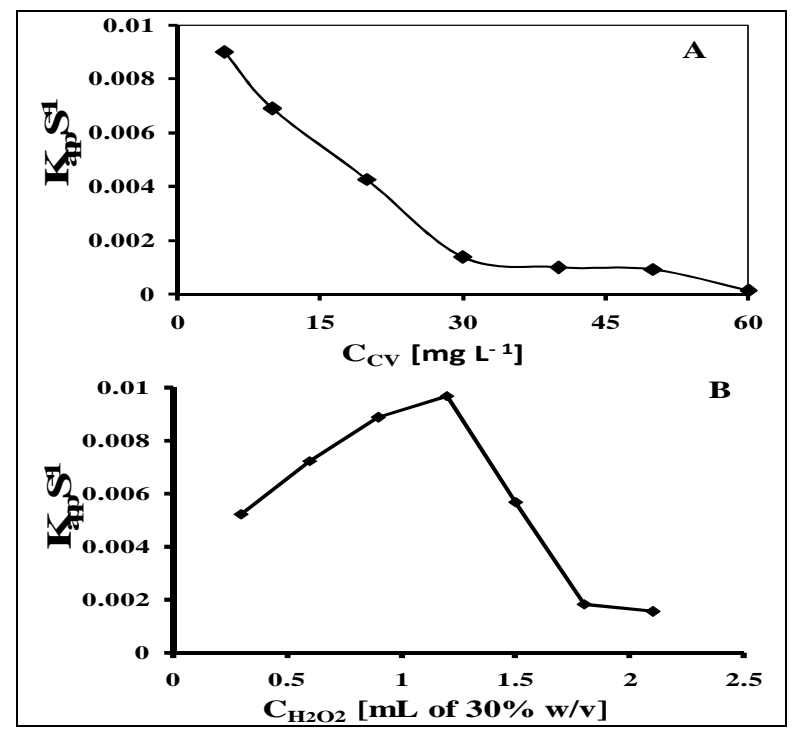

Figure 10. Kinetics mechanism of photocatalytic degradation

(a) Apparent rate constant $\mathrm{K}_{\text {app }}$ versus concentration of $\mathrm{CV}$ (b) Apparent rate constant $\mathrm{K}_{\text {app }}$ versus concentration of $\mathrm{H}_{2} \mathrm{O}_{2}$

\section{Conclusion}

In the current research work, effective heterogeneous photocatalyst MFN were successfully produced by a simple co-precipitation strategy. The synthesized MFN was characterized by FTIR, XRD, EDX and SEM for their component analysis, crystalline structure, phase, elemental analysis, size and morpholygy. The MFN explained semi sphere-shaped geometry with an average particle size range 20 to $50 \mathrm{~nm}$. The photocatalytic results reveals that MFN explain very fast photodegradation of $\mathrm{CV}$ dye with the degradation rate of $>90 \%$ within the time period 60 min. The kinetic analysis established that the photodegradation reaction was following the Langmuir-Hinshelwood approach.

\section{References}

1. R. Ahmed, J. Hazard. Mater., 171 (2009) 767.

https://doi.org/10.1016/j.jhazmat.2009.06.060

2. A. Mittal, J. Mittak, A. Malviya, D. Kaur and V. K. Gupta, J. Colloid Interface Sci., 343 (2010) 463.

https://doi.org/10.1016/j.jcis.2009.11.060

3. S. Li, Biores. Technol., 101 (2010) 2197. https://doi.org/10.1016/j.biortech.2009.11.044

4. K. P. Singh, S. Gupta, A. K. Singh and S. Sinha, J. Hazard. Mater., 186 (2011) 1462. https://doi.org/10.1016/j.jhazmat.2010.12.032

5. C. Sahoo, A. K. Gupta and A. Pal, Dyes Pigm., 66 (2005) 189. https://doi.org/10.1016/j.dyepig.2004.09.003

6. M. Saquib and M. Muneer, Dyes Pigm., 56 (2003) 37.

https://doi.org/10.1016/S01437208(02)00101-8

7. S. Mani and R. N. Bharagava, Rev. Environ. Contam. Toxicol., 237 (2016) 71. https://doi.org/10.1007/978-3-319-23573-8_4

8. H. S. Peavy, D. R. Rowe and G. Tchobanoglous, Environmental Engineering McGraw-Hill, New York, (1985).

9. C. Vidya, M. N. C. Prabhab and M. A. L. A. Raja, Environ. Nanotechnol. Monit. Manag., 6 (2016) 134. 
https://doi.org/10.1016/j.enmm.2016.09.004

10. S. Ameen, M. S. Akhtar, M. Nazim and H. S. Shin, Mater. Lett., 96 (2013) 228. https://doi.org/10.1016/j.matlet.2013.01.034

11. N. M. Mahmoodi, Desalin. Water Treat., 53 (2013) 84. https://doi.org/10.1080/19443994.2013.834519

12. M. M. Sajid, S. B. Khan, N. A. Shad, N. Amin and Z. Zhang, RSC Adv., 8 (2018) 23489.

https://doi.org/10.1039/C8RA03890B

13. B. Sahoo, S. K. Sahu, S. Nayak, D. Dhara and P. Pramanik, Catal. Sci. Technol., 2 (2012) 1367.

https://doi.org/10.1039/c2cy20026k

14. X. Wang, P. Wua, Z. Huang, N. Zhu, J. Wu, P. Lia, Z. Dang, Appl. Clay Sci., 95 (2014) 95.

https://doi.org/10.1016/j.clay.2014.03.016

15. R. Liu, C. F. Wu, and M. D. Ger, $J$. Nanomater., 2015 (2015) 1.

http://dx.doi.org/10.1155/2015/651021

16. R. D. Ambashta and M. Sillanpaa, J. Hazard. Mater., 180 (2010) 38.

https://doi.org/10.1016/j.jhazmat.2010.04.105

17. S. An, X. Liu, L. Yang and L. Zhang, Chem. Eng. Res. Des., 94 (2015) 726. https://doi.org/10.1016/j.cherd.2014.10.013

18. L. Zhang, J. Lian, L. Wang, J. Jiang, Z. Duan and L. Zhao, Chem. Eng. J., 241 (2014) 384. https://doi.org/10.1016/j.cej.2013.10.071
19. X. Liu, T. Zhang and L. Zhang, Sep. Purif. Tech., 195 (2018) 192. https://doi.org/10.1016/j.seppur.2017.12.015

20 D. H. K. Reddya, Y. Yun, Coord. Chem. Rev., 315 (2016) 90. http://dx.doi.org/10.1016/j.ccr.2016.01.012

21. M. T. Shah, A. Balouch, P. Panah, K. Rajar, A. M. Mahar, A. Khan, M. S. Jagirani and H. Khan, J. Electron. Mater., 47 (2018) 5321. https://doi.org/10.1007/s11664-018-6409-0

22. D. L. Pavia, G. M. Lampman and G. S. Kaiz, Introduction to Spectroscopy: A Guide for Students of Organic Chemistry, W.B. Saunders Company, Philadelphia, (1987).

23. P. Laokul, V. Amornnkitbamrung, S. Serphin and S. Maensiri, Cur. Appl. Phys., 11 (2011) 101. https://doi.org/10.1016/j.cap.2010.06.027

24. I. Elahi, R. Zahira, K. Mehmood, A. Jamil and N. Amin, Afr. J. Pure Appl. Chem., 6 (2012) 1 . https://doi.org/10.5897/AJPAC11.054

25. M. T. Shah, A. Balouch, K. Rajar, Sirajuddin, I. A. Brohi, and A. A. Umar, ACS Appl. Mater. Interfaces, 7 (2015) 6480. https://doi.org/10.1021/am507778a

26. A. Hu, G. T. Yee and W. Lin, J. Am. Chem. Soc., 127 (2005) 12486. https://doi.org/10.1021/ja053881o 